\title{
PEMBUATAN BATIK JUMPUT TEKNIK IKAT DESA GROGOL
}

\author{
Eko Cahyo Prawoto' ${ }^{1)}$, Risni Dwi Wahyuni, Miftachul Jannah' ${ }^{2)}$, Ika Candra Agustin ${ }^{3)}$, Satya \\ Diwangkara $\left.{ }^{4}\right)$ \\ 1,2,4 Fakultas Keguruan dan Ilmu Pendidikan, Universitas PGRI Adi Buana Surabaya \\ ${ }^{3}$ Fakultas Ekonomi, Universitas PGRI Adi Buana Surabaya \\ Email: ${ }^{1}$ eko.cahyo@unipasby.ac.id, ${ }^{2}$ risnidwiwahyuni@gmail.com
}

\begin{abstract}
Abstrak
Batik jumput adalah batik yang dikerjakan dengan cara tie dyeing, diikat dengan tali dan diwarnai dengan warna. Batik ini tidak menggunakan malam, tetapi kain diikat, dijahit, atau kusut menggunakan tali. Ada dua teknik untuk membuat batik jumput, yaitu teknik penjilidan dan penjahitan. Teknik pengikatan adalah membuat pola batik jumput dengan mengikat erat kain dengan tali karet atau rafia agar warnanya tidak masuk kain, sedangkan teknik menjahitnya adalah membuat pola terlebih dahulu kemudian dijahit menggunakan tusukan jahitan pada garis warna menggunakan ban, maka benang ditarik kuat sehingga kain keriput sedekat mungkin. Saat dicelup, benang yang rapat akan menghalangi warna memasuki kain. Benang yang digunakan harus berupa benang tebal dan kuat seperti benang plastik atau sintetis, benang jeans, atau benang sepatu. Sosialisasi jumput batik diadakan pada hari Senin, 18 Februari 2019, di Aula Desa Grogol, Kecamatan Tulangan, Kabupaten Sidoarjo dengan pengumpulan data dalam bentuk dokumentasi. Subjek dalam sosialisasi ini adalah wanita PKK dari Desa Grogol, Kabupaten Tulangan, Kabupaten Sidoarjo. Sosialisasi pembuatan lompatan batik pada ibu-ibu PKK diharapkan dapat memberikan pengetahuan baru untuk menggunakan kain bekas atau kain yang belum pernah digunakan untuk digunakan dan dapat digunakan kembali.
\end{abstract}

Kata kunci: batik, jumput, teknik mengikat

\begin{abstract}
Batik jumput is batik which is done by tie dyeing, tied with a rope and dyed with color. This batik does not use night, but the fabric is tied, sewn, or wrinkled using a rope. There are two techniques for making batik jumput, namely binding and stitching techniques. The binding technique is to make a batik jumput pattern by tying tightly the fabric with rubber or raffia straps so that the color does not enter the fabric, while the stitching technique is to make a pattern first then sewn using a stab stitch on the color line using a ban, then the thread is pulled strong so that the fabric wrinkles as close as possible. When dyed, tight threads will block the color from entering the fabric. The yarn used should be thick and strong threads such as plastic or synthetic yarns, jeans threads, or shoe threads. The socialization of batik jumput was held on Monday, February 18 ${ }^{\text {th }}, 2019$, at the Grogol Village Hall, Tulangan Subdistrict, Sidoarjo Regency with data collection in the form of documentation. The subjects in this socialization were PKK women from Grogol Village, Tulangan District, Sidoarjo Regency. The socialization of making batik jump on PKK mothers is expected to provide new knowledge to use used cloth or cloth that has not been used to be used and can be used again.
\end{abstract}

Keywords: batik, jumput, binding technique 


\section{PENDAHULUAN}

Trend fashion yang semakin berkembang, memberi pengaruh positif terhadap pengrajin kain yang terus berkreasi dan berinovasi. Pengrajin kain mampu menciptakan inovasi untuk memunculkan kreasi bahan sandang baru. Inovasi bisa dikembangkan dengan cara apapun, inovasi bahan, inovasi teknik, atau inovasi yang lainnya. Misalnya, batik jumputan. Batik jumputan merupakan kreasi dari para pengrajin dalam memadukan beberapa teknik yang mampu menghasilkan kain yang unik dan memiliki nilai artistik (keindahan) tersendiri.

Membatik pada hakikatnya sama dengan melukis di atas kain dengan menggunakan canting sebagai alatnya dan cairan malam sebagai bahan untuk melukisnya. Pengertian batik adalah memberikan motif pada media dengan proses tutup celup. Berbagai macam motif batik yang diterapkan pada benda-benda menjadikan benda tersebut banyak digemari dan diminati oleh masyarakat, khususnya hasil batik pada kain.

Batik memiliki fungsi ganda, yaitu fungsi praktis, kain batik dapat dipergunakan untuk memenuhi kebutuhan sehari-hari, seperti pakaian, penutup tempat tidur, taplak meja, sarung bantal, dan sebagainya. Secara estetis (keindahan), batik juga bisa dijadikan sebagai hiasan yang menarik seperti: batik lukis yang bisa di bingkai dan bisa dijadikan perhiasan.

Di era globalisasi, batik bukan hanya dijadikan sebagai barang yang memiliki nilai magis dan hanya dimiliki oleh kalangan atas saja, tetapi batik bisa dijumpai di mana-mana dengan motif yang beragam, batik bukan hanya digemari oleh masyarakat Indonesia saja tetapi para turis yang berkunjung ke Indonesia pun tertarik dengan batik. Oleh karena itu, batik perlu dikembangkan dengan motif-motif yang beragam, untuk menambah kekayaan motif-motif batik.

\section{Macam-macam Batik}

Ada 3 macam jenis batik berdasarkan cara pembuatannya.

\section{Batik Jumput}

Batik jumput adalah batik yang dikerjakan dengan cara ikat celup. Kain di ikat dengan tali dan di celup dangan warna. Batik ini tidak menggunakan malam tetapi kainnya diikat, dijahit, atau dikerut dengan menggunakan tali.

Ada dua teknik membuat batik jumputan yaitu teknik ikat dan teknik jahitan. Teknik ikat adalah membuat pola batik jumput dengan cara mengikat kencang kain dengan karet atau tali raffia sehingga warna tidak masuk ke kain, sedangkan teknik jahitan adalah membuat pola terlebih dahulu pada kain lalu dijahit dengan menggunakan tusuk jelujur pada garis warnanya dengan menggunakan banang, lalu benang ditarik kuat sehingga kain berkerut serapat mungkin. Pada waktu dicelup, benang yang rapat akan menghalangi warna masuk ke kain. Benang yang digunakan sebaiknya benang yang tebal dan kuat seperti benang plastik atau sintesis, benang jins, atau benang sepatu. Hasil jumputan teknik jahitan ini berupa titik-titik yang agak menyambung membentuk pola.

\section{Batik Tulis}

Batik tulis adalah hasil dari proses produksi batik dengan teknis pembuatan motifnya ditulis langsung secara manual oleh pembatik. Untuk menulisnya, bisa menggunakan canting yang terbuat dari tembaga yang dilengkapi gagang dari bambu. Ujung dari canting memiliki lubang yang bermacam-macam, sehingga bisa mengaturukuranmotifnya. Selain itu, ada bak penampung canting yang dinamakan dengan nyamplung. Alat ini berisi cairan malam atau pewarna, tergantung dari teknik batik yang nantinya akan digunakan. Batik tulis warna merupakan teknik batik tulis dengan menorehkan cairan malam melalui canting tulis.

\section{Batik Cap}

Batik cap adalah batik yang proses pembatikannya menggunakan canting cap. Canting cap dibuat dengan lempengan kecil bahan tembaga membentuk corak atau motif pada salah satu permukaannya. Permukaan canting cap menggunakan bahan lempengan tembaga tipis dengan alasan bahwa tembaga 
memiliki sifat lentur, mudah dibuat pola dan tahan terhadap panas.

\section{Sejarah Perkembangan Batik Jumput}

Batik dapat berkembang pesat di Indonesia bahkan mulai dikenal di luar negeri. Proses pembuatan batik memang mempunyai ciri tertentu karena keindahannya dan ketelitiannya serta keunikannya, sehingga banyak dikagumi orang-orang asing. Pada mulanya, kain batik hanya dibuat dari bahan kain mori, namun pada masa sekarang berbagai jenis kain seperti primissima, berkolin, santung, belacu, bahkan sutera pun dapat dibuat batik.

Batik jumput adalah batik yang dikerjakan dengan cara ikat celup, di ikat dengan tali di celup dangan warna. Batik ini tidak menggunakan malam, tetapi kainnya diikat atau dijahit dan dikerut dengan menggunakan tali. Tali berfungsi sama halnya dengan malam yakni untuk menutup bagian yang tidak terkena warna.

Menurut sejarah, teknik celup ikat berasal dari Tiongkok. Teknik ini kemudian berkembang sampai ke India dan wilayahwilayah nusantara. Teknik celup ikat diperkenalkan ke nusantara oleh orang-orang India melalui misi perdagangan. Teknik ini mendapat perhatian besar terutama karena keindahan ragam hiasnya dalam rangkaian warna-warni yang menawan. Penggunaan teknik celup ikat ini antara lain di Sumatera, khususnya Palembang, Kalimantan Selatan, Jawa dan Bali.

Dalam proses pewarnaan batik jumput, zaman dahulu, zat pewarna yang digunakan berasal dari alam. Namun, dengan berkembangnya ilmu pengetahuan dan teknologi, zat pewarna alami mulai di tinggalkan. Hal ini terjadi terutama karena pewarna sintesis memiliki jumlah warna yang hampir tak terbatas. Disamping itu, proses pewarnaan alam juga lebih rumit daripada pewarna sintesis. Meskipun demikian, keduanya memiliki keunggulan masingmasing.

Ada dua teknik membuat batik jumputan:

1. Teknik Ikat

Teknik ikat adalah teknik dengan cara ikatan. Artinya, median yang diikat akan menimbulkan motif. Cara mengikatnya harus kencang agar pada saat dicelup, tidak terkena warna, sehingga setelah ikatannya dilepas akan terbentuk pola. Teknik ikat ini dilakukan dengan memegang permukaan kain dengan ujung jari atau menggunakan kelereng, koin, atau batu. Lalu, permukaan kain itu di ikat dengan kencang, baik dengan ikatan tunggal maupun jamak. Cara mengikatnya beragam, seperti ikatan datar, miring, dan kombinasi atau menggunakan teknik lipat dan gulung.

\section{Teknik Jahitan}

Teknik jahitan adalah kain diberi pola terlebih dahulu. Lalu, dijahit dengan menggunakan tusuk jelujur pada garis warnanya dengan menggunakan banang. Lalu, benang ditarik kuat sehingga kain berkerut serapat mungkin. Pada waktu dicelup, benang yang rapat akan menghalangi warna masuk ke kain. Benang yang dipakai sebaiknya benang yang tebal dan kuat seperti benang plastic atau sintesis, benang jins, atau benang sepatu.

\section{METODE PELAKSANAAN}

Sosialisasi pembuatan batik jumput dilaksanakan pada hari Senin, 18 Februari 2019, dan tempat sosialisasi yaitu di Balai Desa Grogol, Kecamatan Tulangan, Kabupaten Sidoarjo dengan pengambilan data berupa dokumentasi. Subjek dalam sosialisasi ini adalah ibu-ibu PKK Desa Grogol yang terdiri dari 30 orang. Pengambilan dokumentasi diambil selama pelaksanaan sosialisasi pembuatan batik jumputan di Balai Desa Grogol, Kecamatan Tulangan, Kabupaten Sidoarjo.

Alat, bahan, dan cara kerja yang digunakan untuk batik jumput adalah sebagai berikut:

\begin{tabular}{l|l}
\multicolumn{1}{c|}{ ALAT } & \multicolumn{1}{c}{ BAHAN } \\
\hline KOMPOR & Air \\
PANCI & Pewarna wenter \\
PENGADUK & Kain putih \\
KELERENG & Soda \\
KARET & TRO \\
TALI RAFFIA & \\
SARUNG & \\
TANGAN &
\end{tabular}




\section{EMBER ATAU \\ BAK}

\section{Cara kerja}

\section{Pembuatan Pola}

1. Siapkan kain, kelereng, karet, dan tali raffia.

2. Membuat pola batik jumput dengan mengikat kelereng pada beberapa bagian kain menggunakan karet atau tali raffia secara kencang dan variatif.

\section{Pewarnaan}

1. Rebus air menggunakan panci hingga mendidih.

2. Basahi kain dengan air bersih.

3. Sebelum mencelupkan kain pada warna, celupkan kain di larutan soda dan TRO.

4. Gunakan sarung tangan untuk mencelupkan kain pada cairan warna. Bila menginginkan satu warna celupkan seluruh bagian kain dalam larutan pewarna yang mendidih

5. Aduk dalam waktu 20-30 menit agar warna merata dan kuat.

6. Bila menginginkan dua warna maka bungkus kain yang dijumput dengan plastik kemudian lakukan step 3, 4, dan 5 .

\section{Pengeringan}

1. Apabila pewarnaan sudah selesai maka angkat kain dari panci.

2. Masukkan kain ke ember yang berisi air biasa dan bersih.

3. Aduk dalam waktu 2-3 menit.

4. Angkat dan jemur kain (dianginanginkan)

5. Batik jumput siap digunakan

Instrumen utama dalam penelitian ini adalah sosialisasi, sedangkan instrumen pendukung adalah dokumentasi.

\section{HASIL DAN PEMBAHASAN}

Sosialisasi pembuatan batik jumput dengan teknik ikat mendapat respon yang sangat baik dari warga Desa Grogol, Kecamatan Tulangan, Kabupaten Siodarjo, khususnya ibu-ibu PKK. Pada saat sosialisasi pembuatan batik jumput teknik ikat, ibu-ibu PKK, pertama-tama, diajarkan cara mengikat kain pada jumputan menggunakan media kelereng untuk isian di dalamnya. Proses mengikat kain membutuhkan waktu yang cukup lama karena kain yang diikat harus kencang agar warna tidak tembus ke bagian yang diikat. Proses pengikatan ini bervariasi sesuai dengan pola yang diinginkan. Setelah proses pengikatan selesai, ibu-ibu PKK diajarakan proses pewarnaan. Proses pewarnaan pada pembuatan batik jumput disebut juga dengan proses pencelupan yaitu pemberian warna secara merata pada bahan tekstil atau kain dengan menggunakan zat warna dan motif tertentu pada kain. Kain yang telah dibuat polanya dengan teknik ikat kemudian diberi warna melalui pencucian awal dengan cara merendam kain dengan TRO dan soda. Proses pencucian awal ini bertujuan agar warna yang akan digunakan dapat merata pada saat pewarnaan.

Proses pembuatan warna menggunakan pewarna wenter yaitu merah dan biru. Saat pencelupan, kain dipijat-pijat dan diremasremas dengan merata, kemudian kain dibalik pada sisi yang lain kemudian dipijat-pijat dan diremas-remas pula. Pencelupan dilakukan tiga kali agar warna lebih pekat, setelah itu kain dijemur dibawah sinar matahari. Pada saat mencelup kain ke TRO dan soda serta pewarna wenter, ibu-ibu PKK menggunakan sarung tangan atau alat bantu untuk mencelup kain tersebut. Setelah dijemur, selanjutnya kain dibilas dengan air bersih lalu dikeringkan.

Kain yang telah melewati proses pembuatan pola dan pewarnaan kemudian dibilas hingga bersih dan dikeringkan, selanjutnya didedel atau dibuka ikatannya. Mendedel ikatan dilakukan dengan hati-hati agar tidak mengakibatkan kain rusak atau sobek. Kain yang sudah melalui proses pembukaan ikatan siap digunakan atau dipasarkan.

Sosilisasi pembuatan batik jumput pada ibu-ibu PKK diharapkan dapat memberi manfaat, seperti:

a. memberi keterampilan baru bagi ibu-ibu PKK tentang cara membuat batik jumput

b. dapat meningkat penghasilan rumah tangga dengan memproduksi batik jumput 
c. mengajari ibu-ibu PKK cara memanfaatkan kain-kain yang tidak digunakan lagi menjadi kain siap pakai atau sebagai hiasan rumah

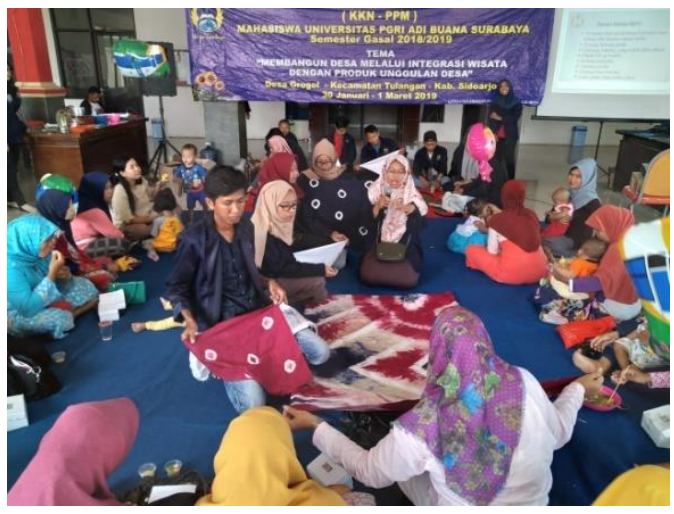

Gambar 1. Sosialisasi pembuatan batik jumput

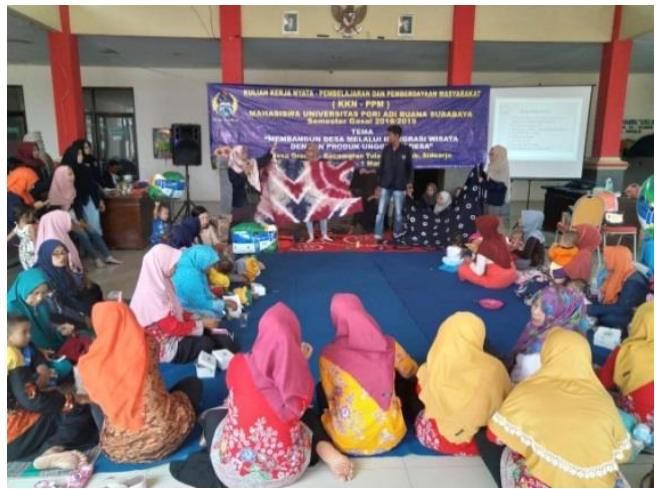

Gambar 2. Proses pembuatan pola batik jumput

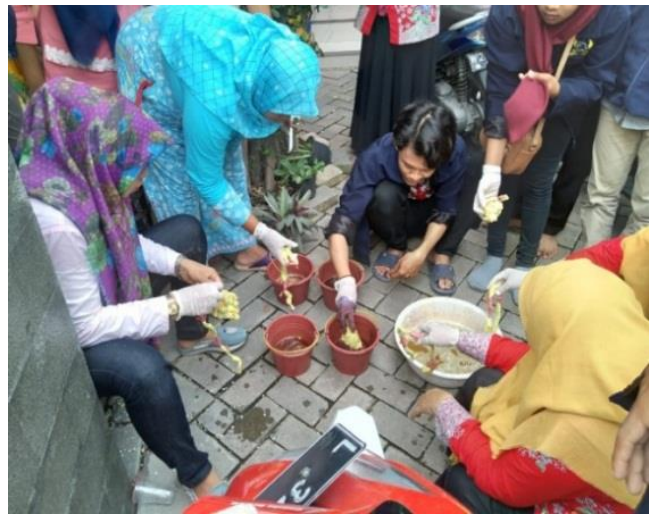

Gambar 3. Proses pewarnaan kain

\section{KESIMPULAN}

Sosialisasi batik jumput sangat bermanfaat bagi ibu-ibu PKK Desa Grogol, Kecamatan Tulangan, Kabupaten Sidoarjo. Dengan membuat batik jumputan dari kain menjadi kain batik, ibu-ibu PKK dapat dengan mudah mengolah kembali kain dan baju yang sudah tidak dipakai dirumah tanpa harus membuangnya. Tidak hanya itu, dengan menggunakan kembali kain dan baju dengan memberikan motif batik jumputan akan mengurangi sampah kain di lingkungan dan dapat digunakan sebagai lapangan pekerjaan yang baru bagi ibu-ibu di Desa Grogol, Kecamatan Tulangan, Kabupaten Sidoarjo.

\section{REFERENSI}

Handoyo, J. D. 2008. Batik dan Jumputan. Yogyakarta: PT. Macanan Jaya Cemerlang.

Juwita, H. K. 2018. Kain Jumputan di Kampung Tahunan Umbulharjo Yogyakarta. Skripsi. Tidak Diterbitkan. Fakultas Bahasa dan Seni. Universitas Negeri Yogyakarta: Yogyakarta.

Ningsih, R. 2001. Mengenal Batik Jumputan. Yogyakarta: Adicita Karya Nusa.

Setiawati, P. 2004. Kupas Tuntas Teknik Proses Membatik Dilengkapi Teknik Menyablon. Yogyakarta: Absolut. Wulandari, A. 2011. Batik Nusantara Makna Filosofis, Cara Pembuatan, dan Industri Batik. Yogyakarta: Andi. 